\title{
Investigating the regional contributions to air pollution in Beijing: a dispersion modelling study using $\mathrm{CO}$ as a tracer
}

\author{
Marios Panagi $^{1,7}$, Zoë L. Fleming ${ }^{1, a}$, Paul S. Monks ${ }^{2}$, Matthew J. Ashfold ${ }^{3}$, Oliver Wild ${ }^{4}$, Michael Hollaway ${ }^{4, b}$, \\ Qiang Zhang ${ }^{5}$, Freya A. Squires ${ }^{6}$, and Joshua D. Vande Hey ${ }^{7}$ \\ ${ }^{1}$ National Centre for Atmospheric Science, Department of Chemistry, University of Leicester, Leicester, UK \\ ${ }^{2}$ Department of Chemistry, University of Leicester, Leicester, UK \\ ${ }^{3}$ School of Environmental and Geographical Sciences, University of Nottingham Malaysia, \\ 43500 Semenyih, Selangor, Malaysia \\ ${ }^{4}$ Lancaster Environment Centre, Lancaster University, Lancaster, UK \\ ${ }^{5}$ Ministry of Education Key Laboratory for Earth System Modeling, Department of Earth System Science, \\ Tsinghua University, Beijing, China \\ ${ }^{6}$ Department of Chemistry, University of York, York, UK \\ ${ }^{7}$ School of Physics and Astronomy, Earth Observation Science Group, University of Leicester, Leicester, UK \\ anow at: Centre for Climate and Resilience Research (CR2), Department of Geophysics, University of Chile, Santiago, Chile \\ ${ }^{b}$ now at: Centre for Ecology and Hydrology, Lancaster Environment Centre, Library Avenue, Bailrigg, Lancaster, UK
}

Correspondence: Marios Panagi (mp558@le.ac.uk) and Joshua D. Vande Hey (jvh7@le.ac.uk)

Received: 24 August 2019 - Discussion started: 4 November 2019

Revised: 17 January 2020 - Accepted: 27 January 2020 - Published: 6 March 2020

\begin{abstract}
The rapid urbanization and industrialization of northern China in recent decades has resulted in poor air quality in major cities like Beijing. Transport of air pollution plays a key role in determining the relative influence of local emissions and regional contributions to observed air pollution. In this paper, dispersion modelling (Numerical Atmospheric Modelling Environment, NAME model) is used with emission inventories and in situ ground measurement data to track the pathways of air masses arriving in Beijing. The percentage of time the air masses spent over specific regions during their travel to Beijing is used to assess the effects of regional meteorology on carbon monoxide $(\mathrm{CO})$, a good tracer of anthropogenic emissions. The NAME model is used with the MEIC (Multi-resolution Emission Inventory for China) emission inventories to determine the amount of pollution that is transported to Beijing from the immediate surrounding areas and regions further away. This approach captures the magnitude and variability of $\mathrm{CO}$ over Beijing and reveals that $\mathrm{CO}$ is strongly driven by transport processes. This study provides a more detailed understanding of relative contributions to air pollution in Beijing under different regional airflow conditions. Approximately $45 \%$ over a 4-year average
\end{abstract}

(2013-2016) of the total CO pollution that affects Beijing is transported from other regions, and about half of this contribution comes from beyond the Hebei and Tianjin regions that immediately surround Beijing. The industrial sector is the dominant emission source from the surrounding regions and contributes over $20 \%$ of the total CO in Beijing. Finally, using $\mathrm{PM}_{2.5}$ to determine high-pollution days, three pollution classification types of pollution were identified and used to analyse the APHH winter campaign and the 4-year period. The results can inform targeted control measures to be implemented by Beijing and the surrounding provinces to tackle air quality problems that affect Beijing and China.

\section{Introduction}

Beijing has suffered from poor air quality during recent decades owing to rapid urbanization and industrialization. Air pollution can have adverse effects on human health and ecosystems; studies have shown that air pollution is a major contributor to the disease burden in China, with over a million attributable premature deaths per year (GBD MAPS 
Working Group, 2016). While air pollution is still at very high levels for human health and the environment (Shi et al., 2019), policy measures implemented over recent years have helped to reduce emissions (Jin et al., 2016; Zheng et al., 2018).

Zheng et al. (2018) conducted an extensive analysis of reductions in anthropogenic emissions of key species in China. Between 2010 and 2017, it is estimated that China reduced its anthropogenic emissions by $62 \%$ for sulfur dioxide $\left(\mathrm{SO}_{2}\right)$, $17 \%$ for nitrogen oxides $\left(\mathrm{NO}_{x}\right), 27 \%$ for carbon monoxide (CO), $38 \%$ for $\mathrm{PM}_{10}$ (particulate matter smaller than $10 \mu \mathrm{m}$ in diameter) and $35 \%$ for $\mathrm{PM}_{2.5}$ (particulate matter smaller than $2.5 \mu \mathrm{m}$ in diameter).

A major contributor to air pollution in Beijing is the transportation of pollutants from other regions owing not just to the major regional sources but also to the meteorology and the topography of Beijing (Wang et al., 2018). Beijing is surrounded by mountains to the north and west of the city, with densely populated industrial areas to the south. The arrival of air masses from the south has been observed to correspond to the formation of pollution episodes (haze events), and air from the north-west leads to the cleansing of the city of pollution (Sun et al., 2016). Zhang et al. (2015) observed the same meteorological pattern with winds from the northwest pushing the pollution away from Beijing, and southerly winds being associated with more polluted days.

Guo et al. (2014) showed that severe pollution episodes in Beijing are largely driven by meteorological conditions. They determined that stagnation usually develops with a weak southerly wind from polluted industrial source regions and that $\mathrm{PM}_{2.5}$ concentrations are anti-correlated with the height of the boundary layer (the lower-most layer of the atmosphere governed by turbulent mixing) in Beijing (Miao et al., 2017). Moreover, the southerly winds transporting aerosols into the city in conjunction with low boundary layer (BL) height can produce heavy aerosol pollution events in Beijing. Tie et al. (2015) reported that during a haze event in October 2013, the $\mathrm{PM}_{2.5}$ concentration in Beijing was $270 \mu \mathrm{g} \mathrm{m}^{-3}$ in southerly winds. The next day the wind direction changed, with winds arriving from the north and the concentration decreased to $50 \mu \mathrm{g} \mathrm{m}^{-3}$. Last but not least, dust storms in Beijing are a resulting of the transportation of natural dust from north-western China, due to dominant north-western winds in the spring (Sugimoto et al., 2003).

Sun et al. (2013) determined that particulate matter levels are higher in the winter owing to increased use of coal. In a survey in 2012, it was reported that almost $85 \%$ of heating energy and $41 \%$ of cooking energy in rural China came from the use of solid fuels (Tao et al., 2018). The use of solid fuels in the residential sector can affect indoor and outdoor air quality and can have harmful effects on both human health and climate change (Desai et al., 2004). Wu et al. (2017) determined during a pollution episode in July 2013 that the contribution of aerosol species in Beijing is dominated by transport from outside Beijing, with contributions exceeding $50 \%$ on average.

To implement effective emission controls it is important to understand the role of transport processes that can influence pollutant levels. In this study, we use dispersion modelling to determine the pathways of air masses and further analysis to determine the transportation of carbon monoxide (CO) to Beijing. The objective of this study is to investigate the impact of regional meteorology and transport on the air pollution in Beijing, and to understand the influence of regional air pollution on Beijing under differing meteorological conditions.

\section{Methods}

\subsection{NAME modelling}

In this study, we used the UK Met Office's Numerical Atmospheric Modelling Environment (NAME) (Jones et al., 2007) to track the pathways of air masses arriving in Beijing. A large number of hypothetical inert particles (hereafter referred to as "air masses") are released and their pathways are tracked backwards in time using meteorological fields from the UK Met Office's Unified Model (Brown et al., 2012). These fields from 1 January 2013 to 15 July 2014 have a horizontal grid resolution of $0.35^{\circ}$ longitude by $0.23^{\circ}$ latitude and from 15 July 2014 to the end of our study period (31 December 2016) have a resolution of $0.23^{\circ}$ longitude by $0.16^{\circ}$ latitude. Throughout, the meteorological fields have 59 vertical levels up to an approximate height of $30 \mathrm{~km}$. The NAME model was chosen as an appropriate model for this study because it uses high-resolution meteorological data of approximately $17 \mathrm{~km} \times 17 \mathrm{~km}$, it can predict dispersion over distances ranging from a few kilometres to the whole globe, and it has been used successfully in similar studies looking at the impact of air mass pathways on air quality (e.g., Fleming et al., 2012; S. Liu et al., 2015; Lowry et al., 2016).

To avoid inconsistency in the resolution of the outputs due to the two different resolutions of the meteorological fields, all the NAME footprints are outputted with the same resolution. The output is a 3-hourly footprint with a resolution of $0.25^{\circ} \times 0.25^{\circ}$, of all the air masses passing through what we define as the surface layer (0-100 ma.g.1.) during their travel to the specified location. For this study, we modelled 5 and $1 \mathrm{~d}$ backward footprints from 2013 to 2016. Figure 1 shows an example footprint for the 19 November 2016 at 18:00 UTC (Coordinated Universal Time). The units are based on a release of a known quantity of air masses (hypothetical particles) in grams (g) during an integrated timeperiod (s) and the results are displayed per grid box, which has a volume component.

To investigate the pathways of air masses arriving in Beijing, we first characterize the air mass pathways based on four quadrants: north-west $(\mathrm{N}-\mathrm{W})$, north-east $(\mathrm{N}-\mathrm{E})$, south- 

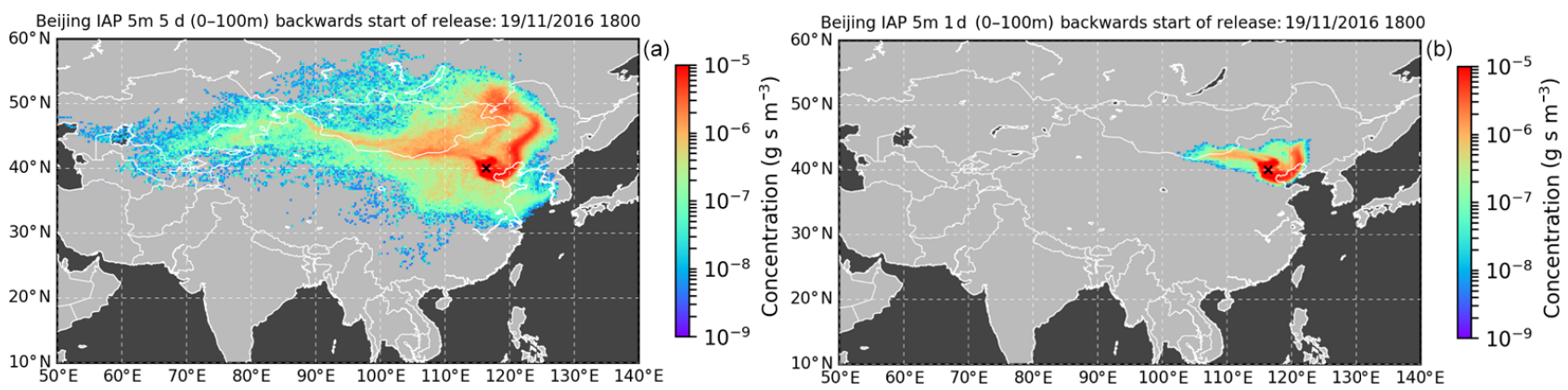

Figure 1. Five-day backwards NAME footprint arriving at IAP meteorological tower (a) and $1 \mathrm{~d}$ backwards NAME footprint arriving at IAP meteorological tower (b).

west (S-W) and south-east (S-E) (see Fig. 2). The four regions intersect at the Institute of Atmospheric Physics (IAP) meteorological tower. The choice of the IAP tower as the centre point was made primarily because the modelled meteorological data could be validated against meteorological data measured from the tower. Figure 3 shows that there is a high degree of similarity between the modelled wind speed and direction (from the meteorological fields) used in NAME and the measured wind speed and direction from the IAP tower. The pathways of the air masses arriving at the IAP tower are important because the chemical and physical composition of an air mass can be influenced by the relative air pollution emissions of the different regions it passes over (Donnelly et al., 2016).

\subsection{CO transport}

We combine the derived NAME footprints and the fluxes from the $\mathrm{CO}$ emission inventories to calculate a modelled mixing ratio of the emitted species at the measurement site (Oram et al., 2017). To do this, first we derive the sensitivities of the measured air masses to emissions occurring within a grid cell (units: $\mathrm{g} \mathrm{m}^{-3} / \mathrm{g} \mathrm{m}^{-2} \mathrm{~s}^{-1}=\mathrm{s} \mathrm{m}^{-1}$ ) and then by multiplying the sensitivities with the emissions from the emission inventories we are able to calculate the modelled CO concentration (dimensionally, $\mathrm{s} \mathrm{m}^{-1} \times \mathrm{g} \mathrm{m}^{-2} \mathrm{~s}^{-1}=$ $\mathrm{g} \mathrm{m}^{-3}$ ). To convert the concentration to a volume mixing ratio we divide the modelled concentrations by the molar mass, divide again by the air density and multiply by $1 \times 10^{9}$. We consider only emissions occurring within the timescale of the NAME footprint. CO is commonly used as a tracer of anthropogenic emissions, as its lifetime of 1-2 months and its weak chemical reactivity make it an appropriate tracer for evaluating regional-scale atmospheric transport (Naeher et al., 2001; Saide et al., 2011).

In this study, the 2013 monthly Multi-resolution Emission Inventory for China (MEIC; Li et al., 2017) emission inventories were used along with the NAME footprint outputs to calculate the pollution transport to Beijing from surrounding regions. MEIC is a bottom-up emission inventory, which covers 31 provinces in mainland China and includes approx-

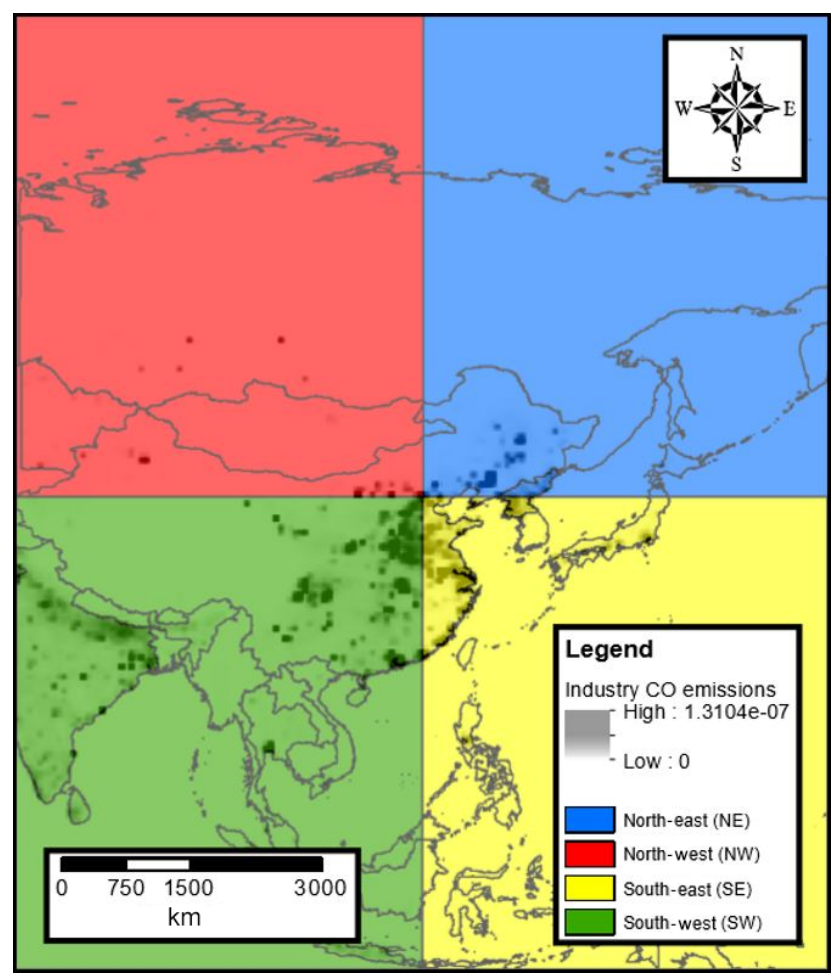

Figure 2. The four quadrants created to investigate the air masses arriving in Beijing. Industry $\mathrm{CO}$ emissions $\left(\mathrm{kg} \mathrm{m}^{2} \mathrm{~s}^{-1}\right)$ from MEIC 2013.

imately 700 anthropogenic sources. The MEIC emission inventories for $\mathrm{CO}$ have a resolution of $0.1^{\circ} \times 0.1^{\circ}$ and are available for four sectors: (a) the industrial sector, (b) the residential sector, (c) the transportation sector and (d) the energy sector. Details of the inventory development and its source classifications can be found in F. Liu et al. (2015). The resolution of the emission inventories was reduced to $0.25^{\circ} \times 0.25^{\circ}$ to match the resolution of the NAME outputs.

The area of interest was split into "regional" to calculate contributions from outside Beijing and "local" to calculate contributions that are emitted from sources within Beijing (Fig. 4). 


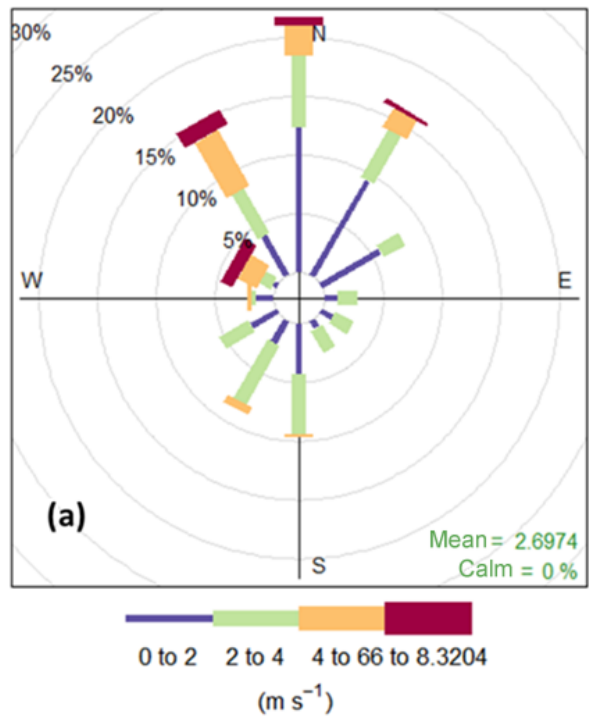

Frequency of counts by wind direction (\%)

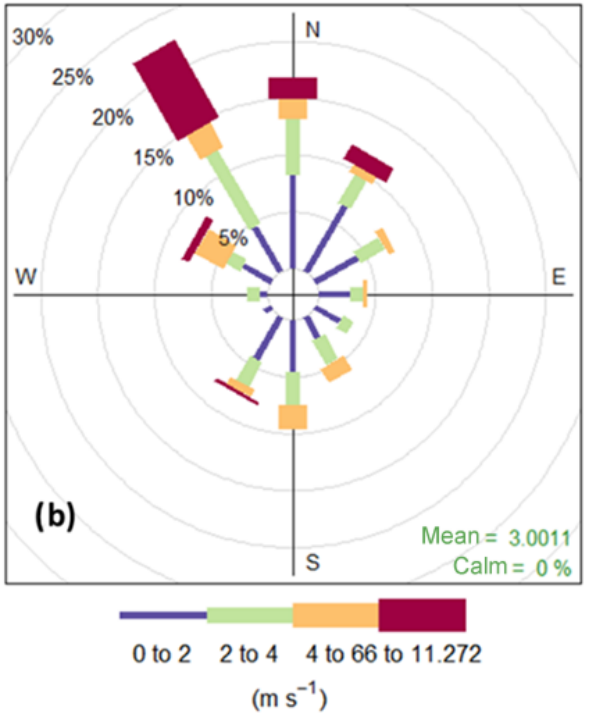

Frequency of counts by wind direction (\%)

Figure 3. (a) Wind rose of the measured met data at $100 \mathrm{~m}$ at the IAP tower, (b) wind rose of the modelled met data at the IAP tower. Both wind roses are for November 2016.

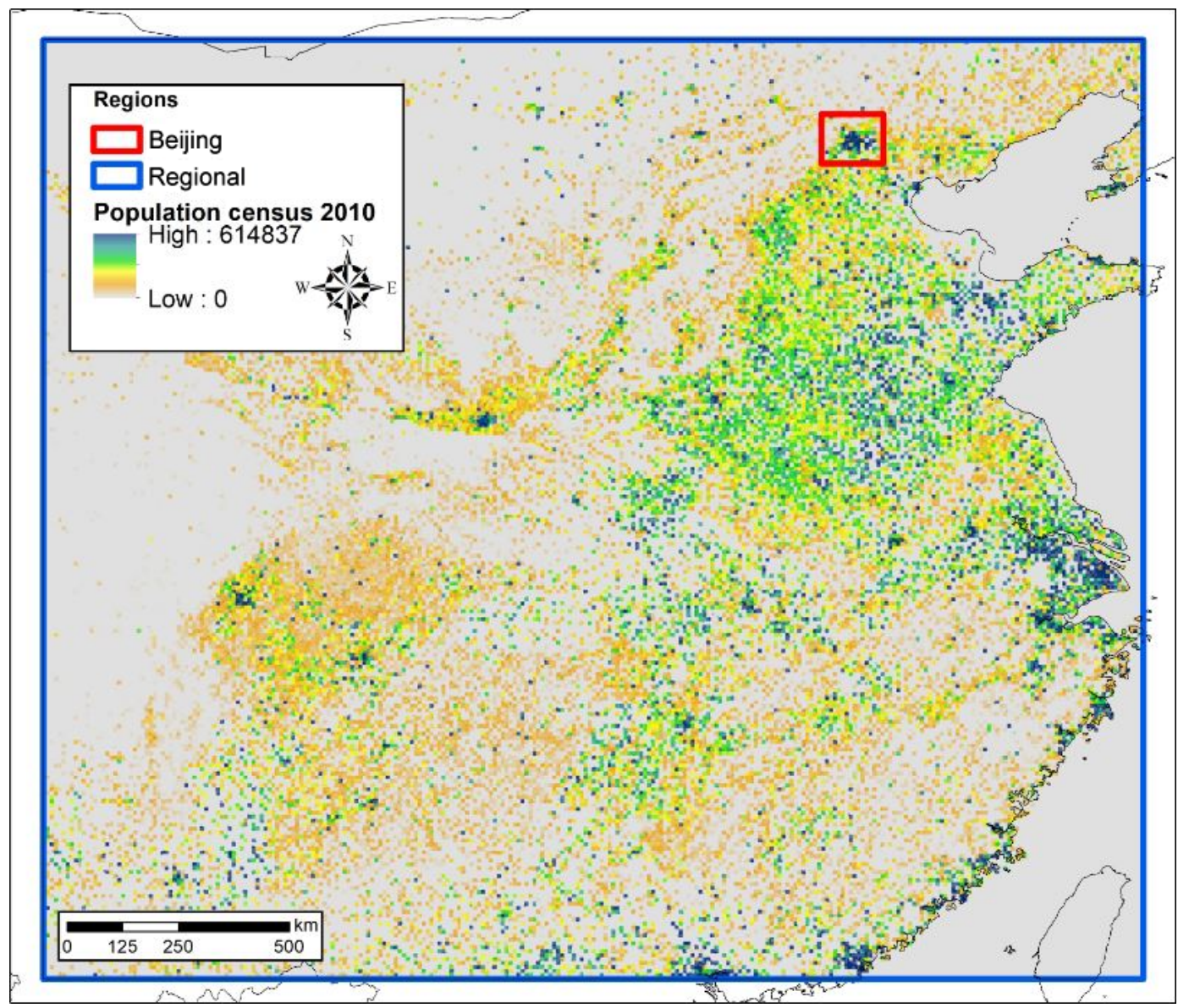

Figure 4. The blue box represents the regional contributions from outside Beijing and the red box is the Beijing region. The map also shows the 2010 population census (people per pixel - WorldPop data, 2015). 


\subsection{In situ measurements}

In this study, two different measurement datasets were used. The first is $\mathrm{CO}$ and $\mathrm{PM}_{2.5}$ measurements for 2013-2016 from 12 air quality monitoring stations around Beijing that are part of the national air quality monitoring network run by the China National Environmental Monitoring Centre (CNEMC). The second dataset contains $\mathrm{CO}$ measurements collected during the winter campaign of the APHH Beijing project that took place from 5 November to 10 December 2016, at the IAP Meteorological tower $\left(39.975^{\circ} \mathrm{N}\right.$, $116.377^{\circ} \mathrm{E}$ ) (Shi et al., 2019). CO measurements at the IAP site were made using six clustered electrochemical sensors (Alphasense Ltd.) encased in a $2 \times 3$ formation. In this study, we use the data collected at the IAP meteorological tower (Shi et al., 2019) to validate the modelled CO data and the CNEMC datasets to compare with our modelled CO from 2013-2016 and determine the pollution events in Beijing using the $\mathrm{PM}_{2.5}$ measurements. The $\mathrm{CO}$ and $\mathrm{PM}_{2.5}$ data from the national air quality network of CNEMC are available on an hourly basis while those from the APHH campaign have a much higher time resolution of $1 \mathrm{~s}$. The analysis in this study is intended to aid interpretation of the vast suite of measurements made during the APHH-Beijing campaign, and for setting these campaigns in an annual and inter-annual context.

\section{Results and discussion}

\subsection{Analysis of transport to Beijing}

The 3-hourly NAME footprints were used to calculate the residence time of the air masses passing over specific regions. The air masses were characterized by season: winter (December, January, February), spring (March, April, May), summer (June, July, August) and autumn (September, October, November), to explore how the pathways change during the year over the four quadrants. The results reveal that the air masses spend more time over the northern quadrants (NW and NE) in all seasons except summer (see Fig. 5). In the summer months there is no dominant pattern, with air masses arriving equally from all four quadrants (see Table 1).

To better understand how and where the air masses travel immediately before they arrive in Beijing, $1 \mathrm{~d}$ backward NAME footprints were analysed. These footprints reveal the path of the air masses on the last day before they arrive in Beijing. From the comparison of the 1 and $5 \mathrm{~d}$ backwards air mass distributions, (Fig. 5) it is observed that the northerly (NW and NE quadrants) distribution is somewhat lower in the $1 \mathrm{~d}$ backward footprints than in the $5 \mathrm{~d}$ backward footprints. This indicates that the air masses spend more time over the southern quadrants just before they arrive in Beijing.

It is therefore important to consider both short- and longrange air mass pathways. For example, when re-circulation
Table 1. Air mass frequency (\%) over each region for the 5 and $1 \mathrm{~d}$ backwards NAME footprints.

\begin{tabular}{rlrrrr}
\hline & & Winter & Spring & Summer & Autumn \\
\hline \multirow{2}{*}{$5 \mathrm{~d}$} & N-E & 11.9 & 14.2 & 20.6 & 19.0 \\
& N-W & 63.2 & 43.3 & 24.0 & 43.8 \\
& S-E & 9.5 & 18.1 & 28.7 & 16.2 \\
& S-W & 15.4 & 24.4 & 26.7 & 21.0 \\
\hline \multirow{2}{*}{$1 \mathrm{~d}$} & N-E & 16.1 & 13.8 & 20.0 & 21.5 \\
& N-W & 51.0 & 32.4 & 21.4 & 35.1 \\
& S-E & 14.4 & 21.1 & 29.4 & 20.4 \\
& S-W & 18.5 & 32.7 & 29.2 & 23.0 \\
\hline
\end{tabular}

of the air masses occurs, the measured wind speed and wind direction from only one station can be misleading. In Fig. 6, two footprints with similar local meteorological conditions are shown; however, the pathways of their arrival at the city are very different, indicating that it is important to have an understanding of synoptic-scale meteorology to effectively determine contributions from other areas. Surface meteorological stations in the city alone are not sufficient for working out contributions from regional air mass transport.

\subsection{Contributions to $\mathrm{CO}$ in Beijing}

Using the technique described in Sect. 2.2, we calculate the expected $\mathrm{CO}$ concentrations arriving at the IAP tower in Beijing at $3 \mathrm{~h}$ intervals and compare these with $\mathrm{CO}$ measurements from the tower during the APHH campaign (Shi et al, 2019). There is generally good agreement between the measured and modelled $\mathrm{CO}$ at the IAP from the $5 \mathrm{~d}$ backward trajectories, with a coefficient of determination of $R^{2}=0.571$; see Fig. 7. Moreover, the coefficient of determination for the 4-year measured $\mathrm{CO}$ and the modelled $\mathrm{CO}$ in Beijing was calculated: $R^{2}=0.479$. The approach appears to account well for the meteorologically driven air mass transport contributions to Beijing pollution and it demonstrates that the variability is governed by the meteorology. Discrepancies between the predictions and observations may be caused by uncertainties in the emission inventory, missing biogenic emissions, secondary $\mathrm{CO}$ production and day-to-day variability in emissions along with small-scale local sources which are not included in the emission inventory. Furthermore, there are uncertainties in the meteorological field simulations owing to the fact that emissions transported to Beijing from outside the $5 \mathrm{~d}$ domain are not included.

Using the CO transportation technique we pair the NAME footprints and the fluxes from the emission inventories on a grid-cell-by-grid-cell basis to calculate the $\mathrm{CO}$. Over the 4-year period from 2013 to 2016 the source sectors contributing most to the total $\mathrm{CO}$ pollution modelled in Beijing are the transportation, industrial and residential sectors, with approximately $37 \%, 34 \%$ and $27 \%$, respectively. The 

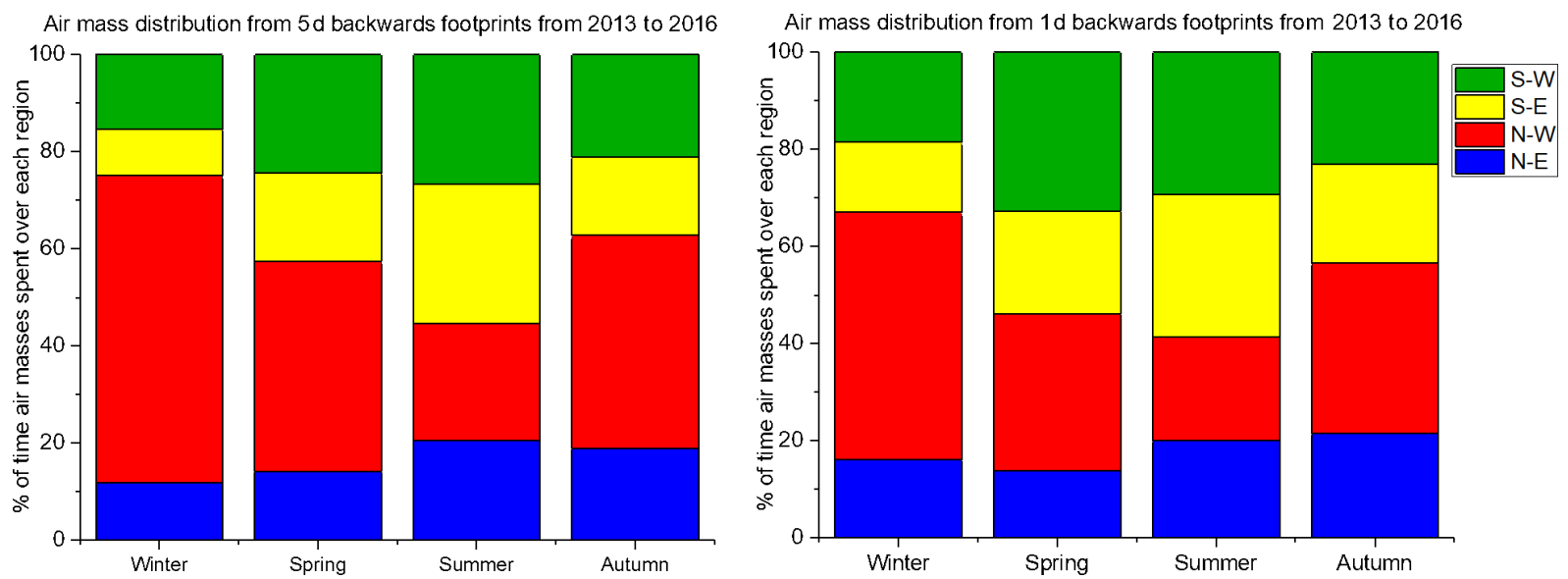

Figure 5. Frequency of the air masses arriving in Beijing from the north-west, north-east, south-west and south-east.

(a)
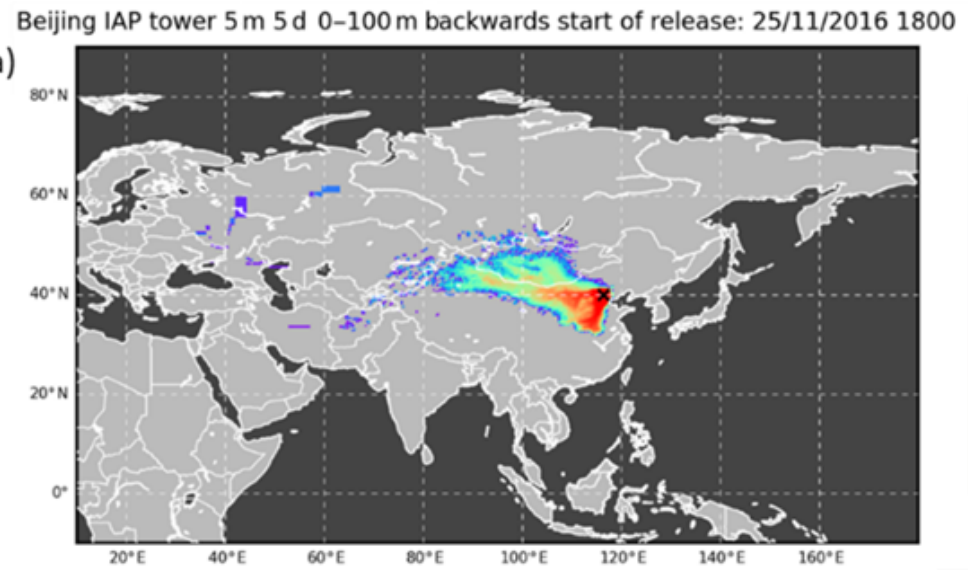

Beijing IAP tower $5 \mathrm{~m} 5 \mathrm{~d} \mathrm{0-100} \mathrm{m} \mathrm{backwards} \mathrm{start} \mathrm{of} \mathrm{release:} \mathrm{25/06/2017} 1800$

(b)

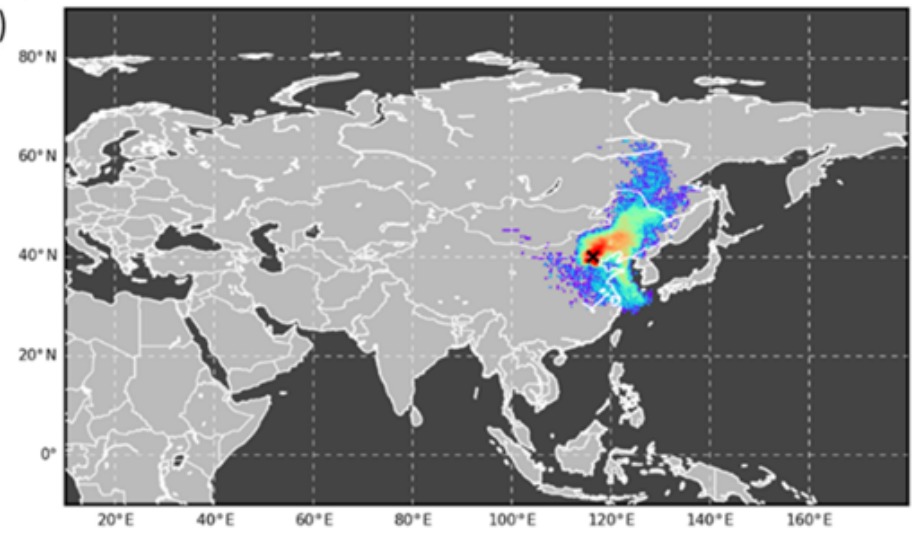

Measured met. data at IAP 25/11/2016

(c)

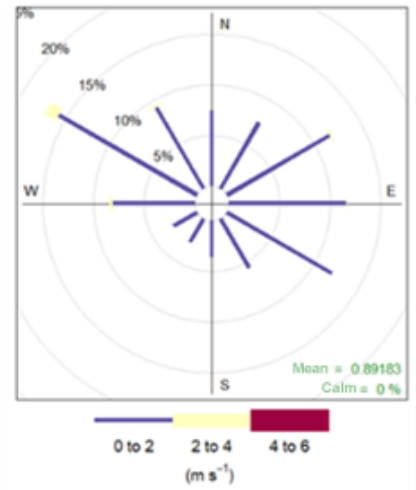

Frequency of counts by wind direction (\%)

Measured met. data at IAP 25/06/2017

(d)

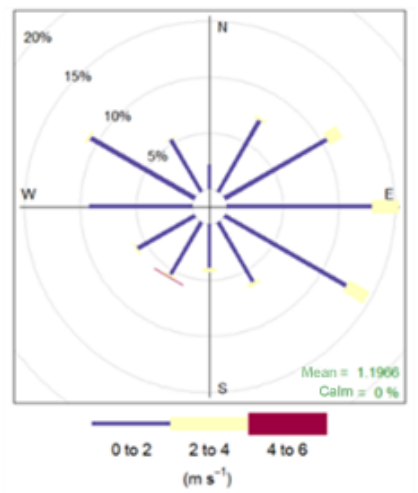

Frequency of counts by wind direction (\%)

Figure 6. Example footprints of air masses arriving in Beijing from the south (a) and north (b) and wind data measured at the ground level during these days $(\mathbf{c}, \mathbf{d})$.

energy sector is the lowest, with a contribution to the total $\mathrm{CO}$ in Beijing of less than $2 \%$ in each season. Sector contributions have different seasonal cycles; the residential sector is highest during the winter months, with an average over 4 years of $637 \mathrm{ppbv}$ ( $45.3 \%$ of total winter modelled CO), and the industrial sector is highest during the summer, with a 4year average of $355 \mathrm{ppbv}$ ( $41.3 \%$ of total summer modelled $\mathrm{CO})$. The emissions from the transportation sector are similar throughout each season; however, their relative contribution 


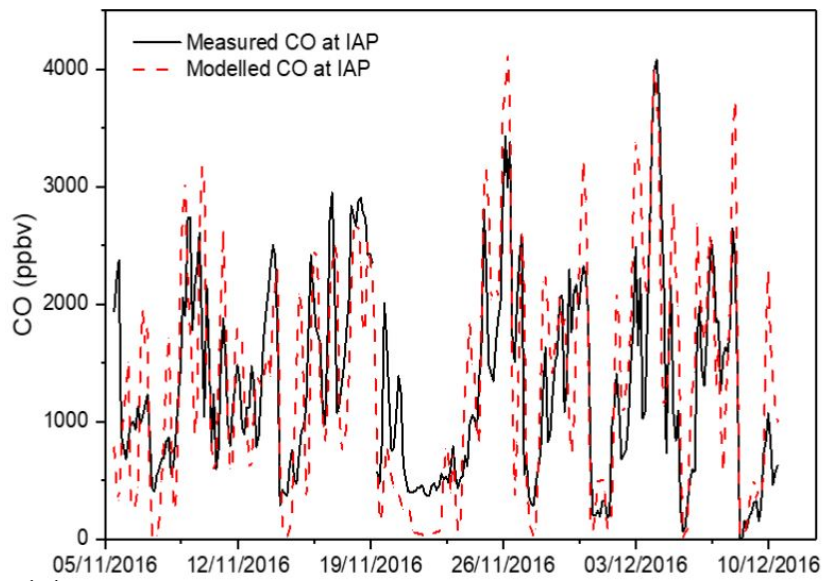

(a)

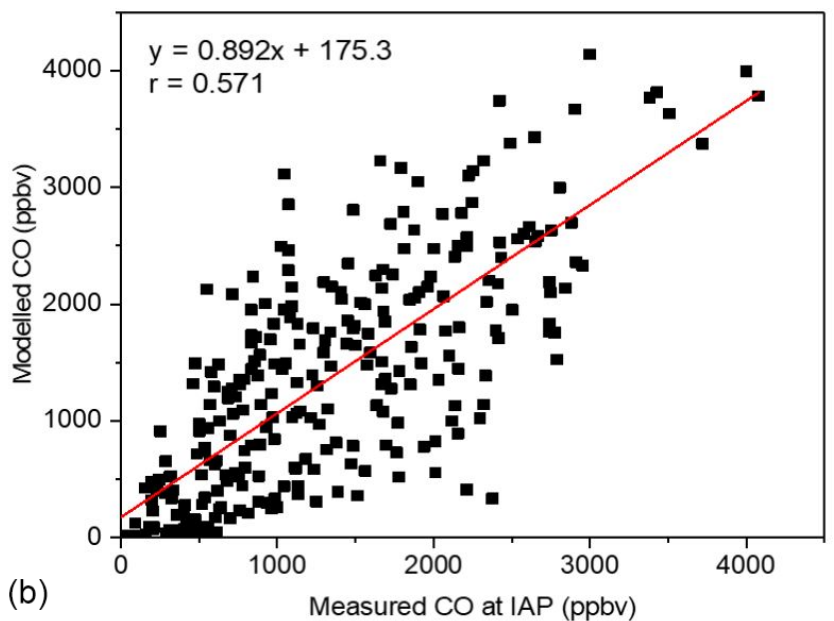

Figure 7. Time series of modelled $\mathrm{CO}$ vs. measured $\mathrm{CO}$ at IAP during the APHH measurement campaign period (a), and correlation of measured and modelled CO (b).

compared to other sectors changes in each season (see sums in Table 2).

By removing local emissions from the MEIC emission inventory, we can isolate the contribution of transport of $\mathrm{CO}$ from emissions in other regions. From the $5 \mathrm{~d}$ backward footprints, we calculate that over a 4-year period, an average of $45 \%$ of the CO in Beijing was transported from outside Beijing. This high contribution is underscored by the study of Wang et al. (2010), which determined that the contribution of $\mathrm{CO}$ from regional sources when local $\mathrm{CO}$ emissions in Beijing are controlled by strict control measures was approximately $77 \%$ in Beijing during the 2008 Olympics. During polluted summer days, Chen et al. (2009) reported that approximately $50 \%$ of the $\mathrm{CO}$ in Beijing is transported from the Tianjin, Shandong and Hebei regions alone, and Cheng et al. (2018) found that regional transport of pollutants contributed almost $60 \%$ of the $\mathrm{PM}_{2.5}$ concentrations in the winter (January 2013), resulting in an extreme regional pollution episode. Furthermore, we determined that the contribution from emissions outside Beijing can reach as high as $80 \%$ of the total CO on some days (as shown in case 2 in Sect. 3.3).

Further analysis was conducted to determine the contributions from each emission sector within Beijing and outside of Beijing using the modelled $\mathrm{CO}$ derived from the analysis of $5 \mathrm{~d}$ backwards footprints and the emission inventories. The highest contribution from the residential sector for regions outside Beijing is during the cold months of winter (see Table 2 and Fig. 8 for seasonal averages for all regions), reaching a maximum 3-hourly contribution of modelled $\mathrm{CO}$ concentration of approximately 1200 ppbv. This can be explained by the greater solid fuel burning during these months (Sun et al., 2013). For other seasons (spring, summer and autumn), the industrial sector was the dominant regional contributor to the $\mathrm{CO}$ pollution in Beijing, peaking at $1300 \mathrm{ppbv}$ and contributing approximately $20 \%$ of the total $\mathrm{CO}$ in Bei- jing. Furthermore, the changes in concentrations and contributions of each sector each season can be also associated with the changes in the air mass pathways and the increase in emissions from other sectors.

The sectoral contributions within Beijing are very different. The dominant sector throughout the year is the transportation sector, which contributes approximately $30 \%$ of the total $\mathrm{CO}$ in Beijing and a maximum 3-hourly concentration of approximately $1600 \mathrm{ppbv}$. The same increase in the residential sector during the winter months was observed within Beijing as was observed outside of Beijing.

The $1 \mathrm{~d}$ backward footprints reveal that on average approximately $80 \%$ of the modelled total CO calculated within the $5 \mathrm{~d}$ footprints is caused by emissions from within the final $24 \mathrm{~h}$ of air mass transport. Moreover, it was determined that the regional $\mathrm{CO}$ air pollution transported from outside Beijing modelled from the $1 \mathrm{~d}$ footprints is approximately half of the pollution transported to Beijing is transported from the immediate surrounding regions (such as Hebei, Tianjin etc.) and the other half from regions further away.

From the comparison of where the air masses spend more time before arriving to Beijing with the percentage of the $\mathrm{CO}$ air pollution transported from the "Regional China" region (Fig. 9), a clear seasonal pattern is observed. The seasonal pattern in the air masses is similar to the seasonal pattern in the CO contribution from Regional China; when the air masses spend more time over the south quadrants (S-E and $\mathrm{S}-\mathrm{W}$ ) before arriving in Beijing, the regional contribution to the CO pollution in Beijing is higher. This clear seasonality suggests that the regional $\mathrm{CO}$ contribution is highly influenced by emissions from the southern regions.

The yearly averages of the modelled $\mathrm{CO}$ for 1 and $5 \mathrm{~d}$ backward footprints and of the measured $\mathrm{CO}$ averaged over the 12 air quality stations in Beijing exhibit no major year-toyear variations (Table 3 ). While our model analysis is limited 
Table 2. Sector CO pollution contribution to Beijing from each region.

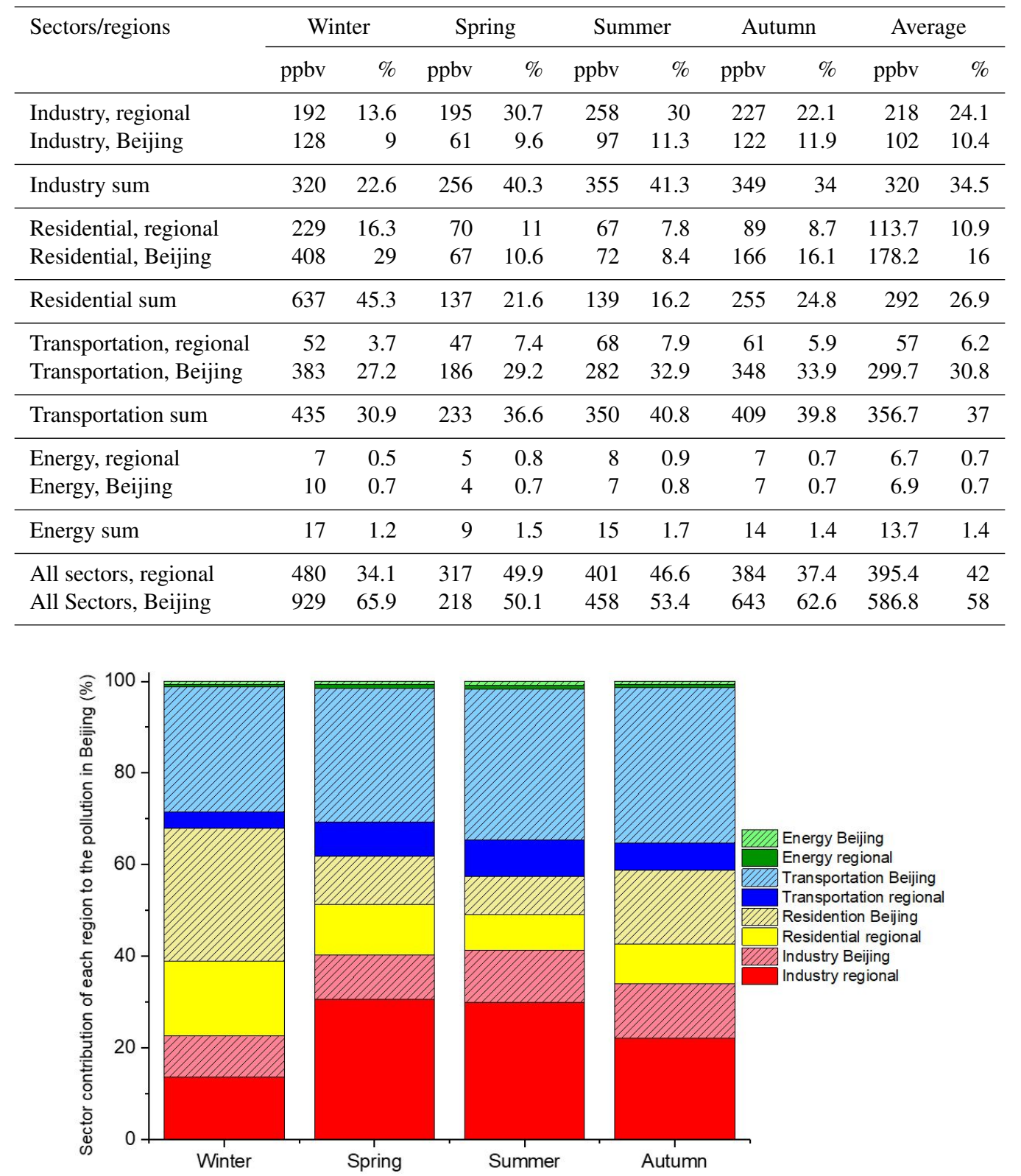

Figure 8. Sector contribution from outside Beijing and within Beijing.

by the MEIC emission inventory existing only for 2013, the consistent year-to-year CO levels indicate the average yearly pathways do not change a lot from year to year. This indicates that we can confidently use the 2013 MEIC CO emission inventories to understand the importance of meteorological variations in pollution transportation to Beijing.

\subsection{Classification of pollution events}

To investigate the relative importance of local and regional emissions during high-pollution events from previous years, the data from CNEMC for $\mathrm{CO}$ and $\mathrm{PM}_{2.5}$ concentrations from 12 monitoring stations in Beijing were used along with the modelled CO. From the measurement dataset, it was calculated that the 4-year average $\mathrm{CO}$ concentration is $1024 \mathrm{ppbv}$ and the maximum concentration is greater than $8000 \mathrm{ppbv}$. The 4-year average $\mathrm{PM}_{2.5}$ concentration is $75 \mu \mathrm{g} \mathrm{m}^{-3}$ with a maximum of $606 \mu \mathrm{g} \mathrm{m}^{-3}$. The WHO limit for $\mathrm{PM}_{2.5}$ is a $25 \mu \mathrm{g} \mathrm{m}^{-3} 24 \mathrm{~h}$ mean and the Chinese level 2 limit is a $75 \mu \mathrm{g} \mathrm{m}^{-3} 24 \mathrm{~h}$ mean (WHO, 2006; Lin et al., 2018). We also consider $\mathrm{PM}_{2.5}$ data here because it is typically the air pollutant of greatest interest from a health per- 
Table 3. Yearly averages of the 1 and $5 \mathrm{~d}$ modelled $\mathrm{CO}$ and the measured average Beijing CO in parts per billion by volume (ppbv).

\begin{tabular}{|c|c|c|c|c|}
\hline & 2013 & 2014 & 2015 & 2016 \\
\hline Modelled $1 \mathrm{~d}_{\text {backwards } \mathrm{CO}} \mathrm{ppbv}^{-1}$ & 721 & 803 & 795 & 786 \\
\hline Modelled $5 \mathrm{~d}$ backwards $\mathrm{CO}_{\mathrm{ppbv}}{ }^{-1}$ & 915 & 994 & 989 & 956 \\
\hline Measured 12 stations Average CO ppbv ${ }^{-1}$ & 1052 & 1005 & 1075 & 962 \\
\hline
\end{tabular}

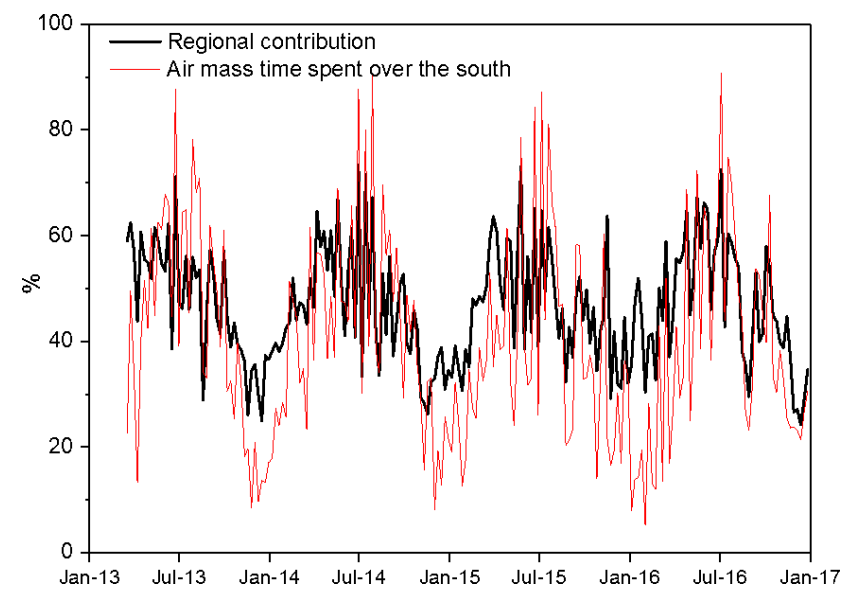

Figure 9. Four-year cycle of contributions from outside Beijing (black line) and the proportion of time (of $5 \mathrm{~d}$ ) spent over southern quadrants (red line).

spective (Lelieveld et al., 2015) and is emitted from similar sources as $\mathrm{CO}$ such as incomplete combustion from sources like transportation, industry and residential areas (Staff and Staff, 2002). This is reflected in the correlation between measured $\mathrm{CO}$ and $\mathrm{PM}_{2.5}$ from all 12 sites used in this study being $r=0.82 . \mathrm{PM}_{2.5}$ and $\mathrm{CO}$ also have similar trends during pollution events and despite $\mathrm{PM}_{2.5}$ having a shorter lifetime than $\mathrm{CO}$, for the short timescales considered here they have similar responses (Shi et al., 2019).

Using the measured $\mathrm{CO}$ and $\mathrm{PM}_{2.5}$, three classification types have been identified as illustrative of different situations, such as when pollution is dominated by local or regional sources or when these contributions are similar. For these classification types, we defined high-pollution events using the $\mathrm{PM}_{2.5}$ Chinese limit level $2\left(>75 \mu \mathrm{g} \mathrm{m}^{-3}\right.$; see Fig. 10d for the average $\mathrm{PM}_{2.5}$ concentration during each classification) and conducted $\mathrm{CO}$ analysis for those periods only. Furthermore, these classification types were also used to analyse pollution events during the winter APHH campaign (see Sect. 3.4).

\section{Classification type 1: pollution dominated by local emissions}

Local emissions dominated (defined as $>65 \%$ contribution to) modelled CO pollution in Beijing approximately $28 \%$ of the time when the $\mathrm{PM}_{2.5}$ concentration was over $75 \mu \mathrm{g} \mathrm{m}^{-3}$.
Between 24 and 28 November 2014, the pollution levels in Beijing were extremely high, with $\mathrm{PM}_{2.5}$ and $\mathrm{CO}$ concentrations reaching $250 \mu \mathrm{g} \mathrm{m}^{-3}$ and $2500 \mathrm{ppbv}$, respectively. We find that during this event less than $30 \%$ of CO was transported from outside Beijing (Fig. 10a). During these days, the contributions from the local sources were very high, with the transportation and the residential sectors accounting for over $2000 \mathrm{ppbv}$ of the $\mathrm{CO}$ in Beijing. The air masses during these days were arriving in Beijing from all directions, which indicates that the transport was possibly very weak.

\section{Classification type 2: pollution dominated by regional contributions}

While the $\mathrm{PM}_{2.5}$ concentration was over $75 \mu \mathrm{g} \mathrm{m}^{-3}$, approximately $32 \%$ of the time the contribution from emissions outside Beijing dominated (defined as $>65 \%$ contribution to the modelled $\mathrm{CO}$ pollution in Beijing). The concentration of $\mathrm{PM}_{2.5}$ peaked at over $200 \mu \mathrm{g} \mathrm{m}^{-3}$ on 31 March 2016, accompanied by CO concentrations of around 1500 ppbv (Fig. 10b). The air masses arriving in Beijing on this day were dominated by air masses that spent most of their time over the southern quadrants before arriving in Beijing. The modelled regional $\mathrm{CO}$ transportation and the dominating southern air mass distribution during this high-pollution day suggest that regional transportation from the south was the main driver of the pollution episode in Beijing.

\section{Classification type 3: similar contribution from regional and local pollution}

When the concentration of $\mathrm{PM}_{2.5}$ was over $75 \mu \mathrm{g} \mathrm{m}^{-3}$, the contributions from local and regional sources of the modelled CO was similar $(50 \pm 15 \%)$ for $40 \%$ of the time during our 4-year study period. An example of these conditions can be seen on 10-12 March 2013 when $\mathrm{PM}_{2.5}$ and CO concentrations reached $100 \mu \mathrm{g} \mathrm{m}^{-3}$ and $1500 \mathrm{ppbv}$, respectively. We find that approximately $50 \%$ of the modelled CO was emitted within Beijing and the rest was transported from regions outside Beijing. During the 12 March when the pollution levels were at maximum, the air masses spent more time over the southern quadrants, but the pollution levels decreased rapidly when air masses arrived from the northern quadrants (Fig. 10c). 

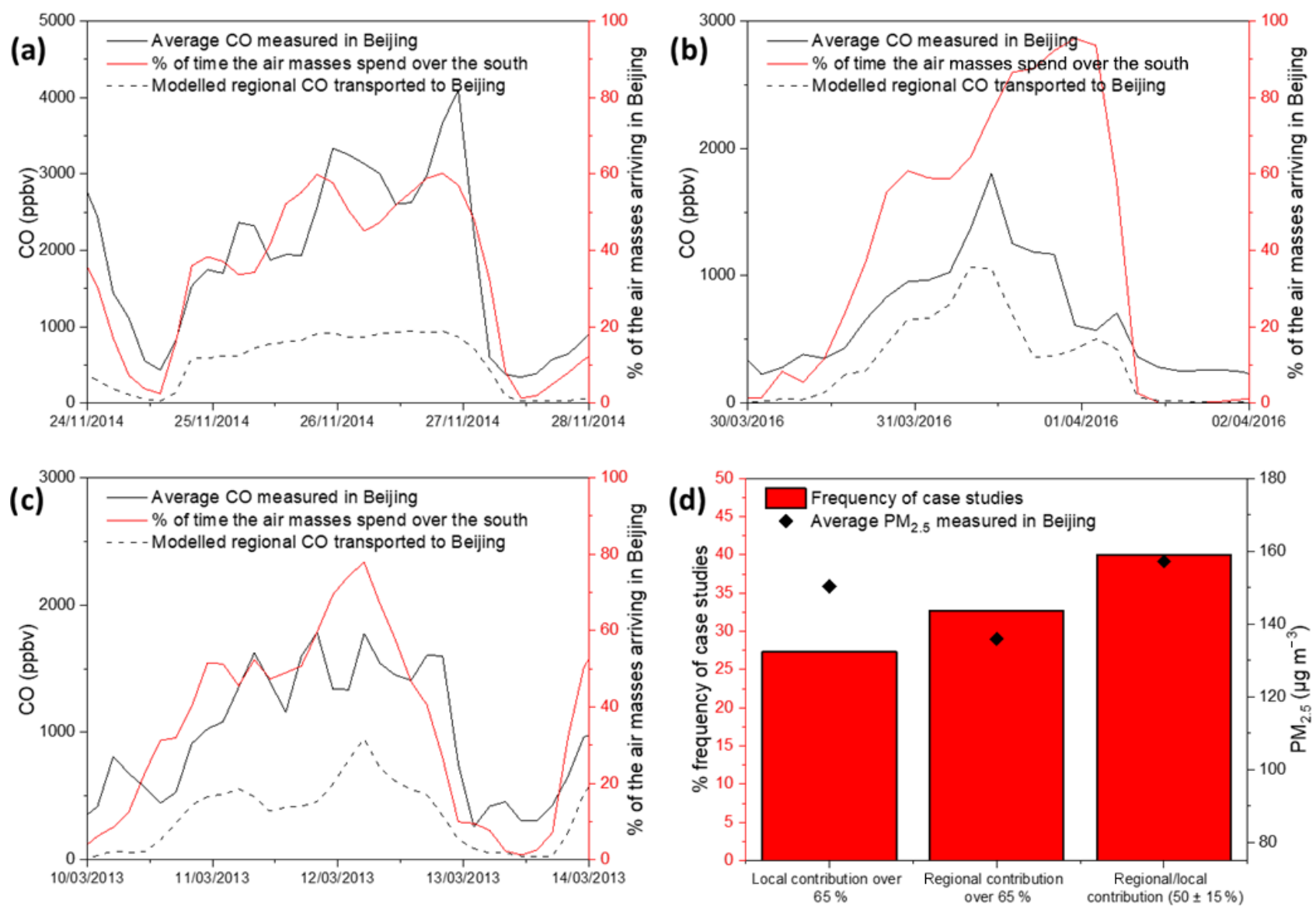

Figure 10. (a-c) Time series of the measured CO, modelled CO transported to Beijing from other regions and the percentages of air masses arriving in Beijing from the south for three case studies, and (d) is the frequency distribution and average $\mathrm{PM}_{2.5}$ for each classifications when the $\mathrm{PM}_{2.5}$ concentration is over $75 \mu \mathrm{g} \mathrm{m}^{-3}$ during 2013-2016.

\subsection{APHH winter campaign}

During the $35 \mathrm{~d}$ of the APHH campaign, $38 \%$ of the modelled $\mathrm{CO}$ arrived from outside Beijing. From the sectors outside of Beijing, the industrial sector is the highest, with an average of $180 \mathrm{ppbv}$; from the sectors within Beijing, the transportation sector is the highest, with 424 ppbv during the campaign. Furthermore, the $1 \mathrm{~d}$ modelled CO makes up $86 \%$ of the $5 \mathrm{~d}$ modelled $\mathrm{CO}$, which indicates that the majority of the $\mathrm{CO}$ transported to Beijing is found in the immediately surrounding areas. The air masses spend approximately $60 \%$ of the time over the north-west quadrant before arriving in Beijing.

Using the three classifications discussed previously when the $\mathrm{PM}_{2.5}$ concentration was over $75 \mu \mathrm{g} \mathrm{m}^{-3}$ during the APHH campaign, it was determined that the pollution was dominated by local contributions approximately $52 \%$ of the time, was dominated by regional contributions $15 \%$ of the time and had similar local and regional contributions $33 \%$ of the time. The highest $\mathrm{PM}_{2.5}$ concentration was recorded when there was a mixture of both local and regional contributions with a 3-hourly average of $400 \mu \mathrm{g} \mathrm{m}^{-3}$.

Furthermore, the average contribution from each classification during the same dates in the three previous years $(5$ November to 10 December, 2013-2015) was calculated. During the previous three years on average, the pollution was dominated by local contributions on average approximately $51 \%$ of the time, the pollution was dominated by regional contributions $8 \%$ of the time, and the pollution in Beijing was a mixture of similar contributions from both the local and regional sources $41 \%$ of the time.

Moreover, during the campaign five haze events were reported (discussed in the APHH project paper, Shi et al., 2019). The haze events are defined as visibility $<10 \mathrm{~km}$ at relative humidity $(\mathrm{RH})<80 \%$ and when $\mathrm{PM}_{2.5}$ is higher than $75 \mu \mathrm{g} \mathrm{m}^{-3}$ (Li et al., 2019). The classifications above were applied to those pollution events. We found that during the five haze events, the pollution was dominated by local sources and a mixture of both local and regional contributions (see Fig. 11). Although the haze events are dominated by local sources, the maximum concentrations are a mixture 


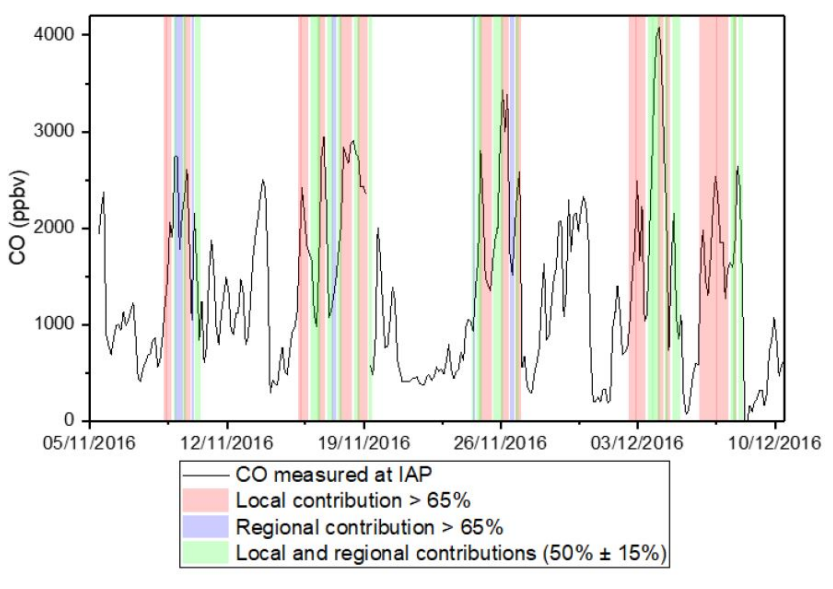

Figure 11. Time series of the measured $\mathrm{CO}$ at the IAP in the winter APHH campaign, during the five haze events where $\mathrm{PM}_{2.5}$ concentration was over $75 \mu \mathrm{g} \mathrm{m}^{-3}$. The colours represent the three classifications observed during the five haze episodes identified in Shi et al. (2019).

of both local and regional sources. Two periods between the haze events were polluted but were not classified as haze events due to the visibility and RH. During the first period on 13 November the contributions are a mixture of both local and regional sources and during the second period on 28-30 November the pollution was mainly dominated by the local sources.

\section{Conclusions}

In this study, we demonstrated that the dispersion modelling approach used provides a valuable way of assessing regional transport impacts and is able to explain variations in $\mathrm{CO}$ over Beijing. The variability in $\mathrm{CO}$ is clearly driven by meteorological processes (e.g., good correlation in Fig. 6) and reflects varying contributions from local and regional sources.

Averaged over the 4-year period from 2013 to 2016, the highest contributors to the total $\mathrm{CO}$ pollution in Beijing are the transportation, industrial and residential sectors with approximately $36 \%, 33 \%$ and $29 \%$ respectively. From the results in this paper, it is clear that transportation of pollutants owing to the meteorology in China can strongly influence the pollution in Beijing. The contribution of $\mathrm{CO}$ pollution from outside Beijing can account on average over the 4 years for up to approximately $45 \%$ of the total $\mathrm{CO}$ pollution in Beijing, with $23 \%$ being transported to Beijing from the immediate surrounding areas and $22 \%$ from areas further away.

The main contributor to the $\mathrm{CO}$ pollution from outside Beijing was the industrial sector, with approximately $20 \%$ contribution on average to the total $\mathrm{CO}$ in Beijing, resulting from the many heavily industrial areas south of Beijing. The residential sector contribution from outside Beijing is very high, contributing $45 \%$ of the $\mathrm{CO}$ in Beijing during the cold months of the winter, because of the coal combustion and solid fuel burning used for cooking and heating.

Although meteorology and regional transportation of $\mathrm{CO}$ are significant contributors to the $\mathrm{CO}$ pollution levels in Beijing, the pollution that is emitted within Beijing is still at very high levels, with an average of $55 \%$ of $\mathrm{CO}$ pollution in Beijing. Within Beijing, the main contributor is the transportation sector, with contributions of $25 \%$ of the total $\mathrm{CO}$ in Beijing.

The classifications revealed that over the 4-year period, when the $\mathrm{PM}_{2.5}$ concentration in Beijing was over $75 \mu \mathrm{g} \mathrm{m}^{-3}$, $32 \%$ of the time $\mathrm{CO}$ in Beijing was strongly dominated by the emissions from outside Beijing and $27 \%$ of the time the pollution was dominated by local emissions. However, the highest mean concentration for $\mathrm{PM}_{2.5}$ was observed during the classification where there is similar contribution from sources within Beijing and outside Beijing. Furthermore, using the same classifications for the APHH winter campaign 2016 , it was observed that the pollution was dominated by local contributions $52 \%$ of the time, by regional contributions $15 \%$ of the time, and by similar local and regional contributions $33 \%$ of the time. During the APHH campaign, a slight increase is observed in the regional contributions compared to the previous 3 years.

When the air masses arriving in Beijing spend more time over the southern quadrants, the contribution from the emission outside Beijing to the pollution levels in Beijing also increases. This indicates that other pollutants such as $\mathrm{PM}_{2.5}$ and volatile organic compounds (VOCs) could be transported similarly depending upon their lifetime in the atmosphere. For short-lived pollutants especially, the results suggested that they can be effectively transported to Beijing from the immediate surrounding regions.

The results lend further weight to the need for a combination of local and regional air quality control measures:

- On average, $55 \%$ of the CO pollution in Beijing is emitted within the city and $45 \%$ is transported in from surrounding regions, emphasizing the need for joined up local and regional air quality management strategies.

- Case studies (small sample size) suggest that for approximately one-third of air pollution episodes, greater than $65 \%$ of the $\mathrm{CO}$ contribution is from regional sources, highlighting the key role transported pollution plays in poor air quality events.

- Control measures may be more effective when they take into account the seasonality both of the regional meteorology and of the relative emissions sector contributions (see Table 2). For example, while Beijing traffic $\mathrm{CO}$ emission reductions should be applied throughout the year, additional controls in the summer might prioritize regional industrial CO reductions, whereas additional winter controls might prioritize Beijing residential $\mathrm{CO}$ reductions. 
The uncertainties in the datasets (emission inventories, measured data and modelled data), especially in the emission inventories, need to be understood better. Furthermore, more research needs to be done to understand the regional contribution to Beijing of pollutants such as $\mathrm{PM}_{2.5}$, VOCs and ozone. Understanding the effect of the meteorology on the regional transport of pollutants to Beijing is very important for new emission control measures.

Data availability. Atmospheric measurement data used in this study are available from the CEDA data archive at https: //catalogue.ceda.ac.uk/uuid/648246d2bdc7460b8159a8f9daee7844 (last access: 2 February 2020) (Fleming et al., 2017). Dispersion model footprints are available from CEDA at https: //catalogue.ceda.ac.uk/uuid/88f3a3de77354692aeada98c5dad599b (last access: 2 February 2020) (Panagi and Fleming, 2017). The modelled data in this study (modelled CO and air mass distribution) are available from the corresponding authors upon request.

Author contributions. MP performed the modelling and numerical data analysis and led the manuscript development. ZLF contributed to the development of the modelling and visualization technique. PSM contributed to research question framing and vision and the manuscript. MJA provided CO transport code and ideas on analysis and contributed to the manuscript. OW provided ideas on analysis and contributed to the manuscript, MH converted MEIC inventories for use. QZ contributed MEIC inventory data. FAS collected the CO APHH campaign data. JDVH oversaw the research and contributed extensively to the manuscript development and data interpretation.

Competing interests. The authors declare that they have no conflict of interest.

Special issue statement. This article is part of the special issue "In-depth study of air pollution sources and processes within Beijing and its surrounding region (APHH-Beijing) (ACP/AMT interjournal SI)". It is not associated with a conference.

Acknowledgements. We would like to thank the UK Met Office for supplying the Unified Model Meteorological data and the use of the NAME model and the CEDA for providing space on the JASMIN supercomputer to run the model. We thank the University of Leicester's high-performance computing services for supplying the necessary computing power for plotting and storing the model output and Duncan Law-Green at Leicester University for developing the code to plot and interpret the NAME model output. We acknowledge James Lee at York University and the national air quality monitoring network run by the China National Environmental Monitoring Centre for providing the data. We would also like to thank the colleagues at IAP for the access to the tower meteorological data. Finally, we would like to thank the National Centre for Atmospheric Science (NCAS) and NERC for funding.
Financial support. This research has been supported by the National Centre for Atmospheric Science (NCAS), the University of Leicester, and the UK Natural Environment Research Council (grant no. NE/N005406/1 for Joshua D. Vande Hey and grant nos. NE/N006925/1 and NE/N006976/1 for Oliver Wild and Michael Hollaway).

Review statement. This paper was edited by James Allan and reviewed by two anonymous referees.

\section{References}

Brown, A., Milton, S., Cullen, M., Golding, B., Mitchell, J., and Shelly, A.: Unified Modeling and Prediction of Weather and Climate: A 25-Year Journey, B. Am. Meteorol. Soc., 93, 1865-1877, https://doi.org/10.1175/bams-d-12-00018.1, 2012.

Chen, D., Wang, Y., McElroy, M. B., He, K., Yantosca, R. M., and Le Sager, P.: Regional CO pollution and export in China simulated by the high-resolution nested-grid GEOS-Chem model, Atmos. Chem. Phys., 9, 3825-3839, https://doi.org/10.5194/acp-93825-2009, 2009.

Cheng, N., Li, Y., Cheng, B., Wang, X., Meng, F., Wang, Q., and Qiu, Q.: Comparisons of two serious air pollution episodes in winter and summer in Beijing, J. Environ. Sci., 69, 141-154, https://doi.org/10.1016/j.jes.2017.10.002, 2018.

Desai, M., Mehta, S., and Smith, K.: Indoor smoke from solid fuels: Assessing the environmental burden of disease at national and local levels, WHO Environmental Burden of Disease Series, No. 4, World Health Organization, Geneva, 2004.

Donnelly, A., Naughton, O., Misstear, B., and Broderick, B.: Maximizing the spatial representativeness of $\mathrm{NO}_{2}$ monitoring data using a combination of local wind-based sectoral division and seasonal and diurnal correction factors, J. Environ. Sci. Heal. A, 51, 1003-1011, https://doi.org/10.1080/10934529.2016.1198174, 2016.

Fleming, Z., Monks, P., and Manning, A.: Review: Untangling the influence of air-mass history in interpreting observed atmospheric composition, Atmos. Res., 104-105, 1-39, https://doi.org/10.1016/j.atmosres.2011.09.009, 2012.

Fleming, Z. L., Lee, J. D., Liu, D., Acton, J., Huang, Z., Wang, X., Hewitt, N., Crilley, L., Kramer, L., Slater, E., Whalley, L., Ye, C., and Ingham, T.: APHH: Atmospheric measurements and model results for the Atmospheric Pollution \& $\mathrm{Hu}-$ man Health in a Chinese Megacity, Centre for Environmental Data Analysis, available at: https://catalogue.ceda.ac.uk/uuid/ 648246d2bdc7460b8159a8f9daee7844 (last access: 2 February 2020), 2017.

GBD MAPS Working Group: Burden of Disease Attributable to Coal-Burning and Other Major Sources of Air Pollution in China. Special Report 20, Boston, MA, Health Effects Institute, 2016.

Guo, S., Hu, M., Zamora, M., Peng, J., Shang, D., Zheng, J., Du, Z., Wu, Z., Shao, M., Zeng, L., Molina, M., and Zhang, R.: Elucidating severe urban haze formation in China, P. Natl. Acad. Sci. USA, 111, 17373-17378, https://doi.org/10.1073/pnas.1419604111, 2014. 
Jin, Y., Andersson, H., and Zhang, S.: Air Pollution Control Policies in China: A Retrospective and Prospects, Int. J. Environ. Res. Public Health, 13, 1219, https://doi.org/10.3390/ijerph13121219, 2016.

Jones, A., Thomson, D., Hort, M., and Devenish, B.: The UK Met Office's next-generation atmospheric dispersion model, NAME III, Air Pollut. Model. Appl. XVII, 17, 580-589, 2007.

Lelieveld, J., Evans, J., Fnais, M., Giannadaki, D., and Pozzer, A.: The contribution of outdoor air pollution sources to premature mortality on a global scale, Nature, 525, 367-371, https://doi.org/10.1038/nature15371, 2015.

Li, M., Zhang, Q., Kurokawa, J.-I., Woo, J.-H., He, K., Lu, Z., Ohara, T., Song, Y., Streets, D. G., Carmichael, G. R., Cheng, Y., Hong, C., Huo, H., Jiang, X., Kang, S., Liu, F., Su, H., and Zheng, B.: MIX: a mosaic Asian anthropogenic emission inventory under the international collaboration framework of the MICS-Asia and HTAP, Atmos. Chem. Phys., 17, 935-963, https://doi.org/10.5194/acp-17-935-2017, 2017.

Li, Y., Xue, Y., Guang, J., de Leeuw, G., Self, R., She, L., Fan, C., Xie, Y., and Chen, G.: Spatial and temporal distribution characteristics of haze days and associated factors in China from 1973 to 2017, Atmos. Environ., 214, 116862, https://doi.org/10.1016/j.atmosenv.2019.116822, 2019.

Lin, Y., Zou, J., Yang, W., and Li, C.-Q.: A Review of Recent Advances in Research on $\mathrm{PM}_{2.5}$ in China, Int. J. Environ. Res. Public Health, 15, 438, https://doi.org/10.3390/ijerph15030438, 2018.

Liu, F., Zhang, Q., Tong, D., Zheng, B., Li, M., Huo, H., and He, K. B.: High-resolution inventory of technologies, activities, and emissions of coal-fired power plants in China from 1990 to 2010, Atmos. Chem. Phys., 15, 13299-13317, https://doi.org/10.5194/acp-15-13299-2015, 2015a.

Liu, S., Aiken, A., Gorkowski, K., Dubey, M., Cappa, C., Williams, L., Herndon, S., Massoli, P., Fortner, E., Chhabra, P., Brooks, W., Onasch, T., Jayne, J., Worsnop, D., China, S., Sharma, N., Mazzoleni, C., Xu, L., Ng, N., Liu, D., Allan, J., Lee, J., Fleming, Z., Mohr, C., Zotter, P., Szidat, S., and Prévôt, A.: Enhanced light absorption by mixed source black and brown carbon particles in UK winter, Nat. Commun., 6, 8435, https://doi.org/10.1038/ncomms9435, 2015b.

Lowry, D., Lanoisellé, M., Fisher, R., Martin, M., Fowler, C., France, J., Hernández-Paniagua, I., Novelli, P., Sriskantharajah, S., O’Brien, P., Rata, N., Holmes, C., Fleming, Z., Clemitshaw, K., Zazzeri, G., Pommier, M., McLinden, C., and Nisbet, E.: Marked long-term decline in ambient $\mathrm{CO}$ mixing ratio in SE England, 1997-2014: evidence of policy success in improving air quality, Sci. Rep., 6, 25661, https://doi.org/10.1038/srep25661, 2016.

Miao, Y., Guo, J., Liu, S., Liu, H., Li, Z., Zhang, W., and Zhai, P.: Classification of summertime synoptic patterns in Beijing and their associations with boundary layer structure affecting aerosol pollution, Atmos. Chem. Phys., 17, 3097-3110, https://doi.org/10.5194/acp-17-3097-2017, 2017.

Naeher, L., Smith, K., Leaderer, B., Neufeld, L., and Mage, D.: Carbon Monoxide As a Tracer for Assessing Exposures to Particulate Matter in Wood and Gas Cookstove Households of Highland Guatemala, Environ. Sci. Technol., 35, 575-581, https://doi.org/10.1021/es991225g, 2001.
Oram, D. E., Ashfold, M. J., Laube, J. C., Gooch, L. J., Humphrey, S., Sturges, W. T., Leedham-Elvidge, E., Forster, G. L., Harris, N. R. P., Mead, M. I., Samah, A. A., Phang, S. M., Ou-Yang, C.-F., Lin, N.-H., Wang, J.-L., Baker, A. K., Brenninkmeijer, C. A. M., and Sherry, D.: A growing threat to the ozone layer from short-lived anthropogenic chlorocarbons, Atmos. Chem. Phys., 17, 11929-11941, https://doi.org/10.5194/acp-17-119292017, 2017.

Panagi, M. and Fleming, Z. L.: APHH: Atmospheric dispersion model footprint plots made at the IAP-Beijing site during the summer and winter campaigns, Centre for Environmental Data Analysis, available at: https://catalogue.ceda.ac.uk/uuid/ 88f3a3de77354692aeada98c5dad599b (last access: 2 February 2020), 2017.

Saide, P., Carmichael, G., Spak, S., Gallardo, L., Osses, A., Mena-Carrasco, M., and Pagowski, M.: Forecasting urban $\mathrm{PM}_{10}$ and $\mathrm{PM}_{2.5}$ pollution episodes in very stable nocturnal conditions and complex terrain using WRFChem CO tracer model, Atmos. Environ., 45, 2769-2780, https://doi.org/10.1016/j.atmosenv.2011.02.001, 2011.

Shi, Z., Vu, T., Kotthaus, S., Harrison, R. M., Grimmond, S., Yue, S., Zhu, T., Lee, J., Han, Y., Demuzere, M., Dunmore, R. E., Ren, L., Liu, D., Wang, Y., Wild, O., Allan, J., Acton, W. J., Barlow, J., Barratt, B., Beddows, D., Bloss, W. J., Calzolai, G., Carruthers, D., Carslaw, D. C., Chan, Q., Chatzidiakou, L., Chen, Y., Crilley, L., Coe, H., Dai, T., Doherty, R., Duan, F., Fu, P., Ge, B., Ge, M., Guan, D., Hamilton, J. F., He, K., Heal, M., Heard, D., Hewitt, C. N., Hollaway, M., Hu, M., Ji, D., Jiang, X., Jones, R., Kalberer, M., Kelly, F. J., Kramer, L., Langford, B., Lin, C., Lewis, A. C., Li, J., Li, W., Liu, H., Liu, J., Loh, M., Lu, K., Lucarelli, F., Mann, G., McFiggans, G., Miller, M. R., Mills, G., Monk, P., Nemitz, E., O’Connor, F., Ouyang, B., Palmer, P. I., Percival, C., Popoola, O., Reeves, C., Rickard, A. R., Shao, L., Shi, G., Spracklen, D., Stevenson, D., Sun, Y., Sun, Z., Tao, S., Tong, S., Wang, Q., Wang, W., Wang, X., Wang, X., Wang, Z., Wei, L., Whalley, L., Wu, X., Wu, Z., Xie, P., Yang, F., Zhang, Q., Zhang, Y., Zhang, Y., and Zheng, M.: Introduction to the special issue "In-depth study of air pollution sources and processes within Beijing and its surrounding region (APHH-Beijing)", Atmos. Chem. Phys., 19, 7519-7546, https://doi.org/10.5194/acp19-7519-2019, 2019.

Staff, N. and Staff, T.: Ongoing Challenge of Managing Carbon Monoxide Pollution in Fairbanks, Alaska, National Academies Press, Washington, 2002.

Sugimoto, N., Uno, I., Nishikawa, M., Shimizu, A., Matsui, I., Dong, X., Chen, Y., and Quan, H.: Record heavy Asian dust in Beijing in 2002: Observations and model analysis of recent events, Geophys. Res. Lett., 30, 1640, https://doi.org/10.1029/2002GL016349, 2003.

Sun, Y., Du, W., Fu, P., Wang, Q., Li, J., Ge, X., Zhang, Q., Zhu, C., Ren, L., Xu, W., Zhao, J., Han, T., Worsnop, D. R., and Wang, $\mathrm{Z}$.: Primary and secondary aerosols in Beijing in winter: sources, variations and processes, Atmos. Chem. Phys., 16, 8309-8329, https://doi.org/10.5194/acp-16-8309-2016, 2016.

Sun, Y. L., Wang, Z. F., Fu, P. Q., Yang, T., Jiang, Q., Dong, H. B., Li, J., and Jia, J. J.: Aerosol composition, sources and processes during wintertime in Beijing, China, Atmos. Chem. Phys., 13, 4577-4592, https://doi.org/10.5194/acp-13-4577-2013, 2013. 
Tao, S., Ru, M., Du, W., Zhu, X., Zhong, Q., Li, B., Shen, G., Pan, X., Meng, W., Chen, Y., Shen, H., Lin, N., Su, S., Zhuo, S., Huang, T., Xu, Y., Yun, X., Liu, J., Wang, X., Liu, W., Cheng, H., and Zhu, D.: Quantifying the rural residential energy transition in China from 1992 to 2012 through a representative national survey, Nature Energy, 3, 567-573, https://doi.org/10.1038/s41560018-0158-4, 2018.

Tie, X., Zhang, Q., He, H., Cao, J., Han, S., Gao, Y., $\mathrm{Li}, \mathrm{X}$., and Jia, X.: A budget analysis of the formation of haze in Beijing, Atmos. Environ., 100, 25-36, https://doi.org/10.1016/j.atmosenv.2014.10.038, 2015.

Wang, T., Nie, W., Gao, J., Xue, L. K., Gao, X. M., Wang, X. F., Qiu, J., Poon, C. N., Meinardi, S., Blake, D., Wang, S. L., Ding, A. J., Chai, F. H., Zhang, Q. Z., and Wang, W. X.: Air quality during the 2008 Beijing Olympics: secondary pollutants and regional impact, Atmos. Chem. Phys., 10, 7603-7615, https://doi.org/10.5194/acp-10-7603-2010, 2010.

Wang, X., Dickinson, R., Su, L., Zhou, C., and Wang, K.: PM 2.5 Pollution in China and How It Has Been Exacerbated by Terrain and Meteorological Conditions, B. Am. Meteorol. Soc., 99, 105119, https://doi.org/10.1175/bams-d-16-0301.1, 2018.

WHO: WHO Air Quality Guidelines for Particulate Matter, Ozone, Nitrogen Dioxide and Sulfur Dioxide, World Health Organization, Geneva, Switzerland, 2006.
WorldPop (School of Geography and Environmental Science, University of Southampton): China $100 \mathrm{~m}$ Population. Alpha version 2010, 2015 and 2020 estimates of numbers of people per pixel (ppp) and people per hectare (pph), with national totals adjusted to match UN population division estimates, available at: https://www.worldpop.org/geodata/summary?id= 131 (last access: 20 August 2019), and remaining unadjusted, https://doi.org/10.5258/SOTON/WP00055, 2015.

Wu, J., Li, G., Cao, J., Bei, N., Wang, Y., Feng, T., Huang, R., Liu, S., Zhang, Q., and Tie, X.: Contributions of trans-boundary transport to summertime air quality in Beijing, China, Atmos. Chem. Phys., 17, 2035-2051, https://doi.org/10.5194/acp-172035-2017, 2017.

Zhang, L., Wang, T., Lv, M., and Zhang, Q.: On the severe haze in Beijing during January 2013: Unraveling the effects of meteorological anomalies with WRF-Chem, Atmos. Environ., 104, 11-21, https://doi.org/10.1016/j.atmosenv.2015.01.001, 2015.

Zheng, B., Tong, D., Li, M., Liu, F., Hong, C., Geng, G., Li, H., Li, X., Peng, L., Qi, J., Yan, L., Zhang, Y., Zhao, H., Zheng, Y., He, K., and Zhang, Q.: Trends in China's anthropogenic emissions since 2010 as the consequence of clean air actions, Atmos. Chem. Phys., 18, 14095-14111, https://doi.org/10.5194/acp-18-140952018, 2018. 